\title{
The role of language familiarity in voice identification
}

\author{
JUDITH P. GOGGIN \\ University of Texas, El Paso, Texas \\ CHARLES P. THOMPSON \\ Kansas State University, Manhattan, Kansas \\ GERHARD STRUBE \\ Ruhr-Universität, Bochum, Germany \\ and \\ LIZA R. SIMENTAL \\ University of Texas, El Paso, Texas
}

\begin{abstract}
Four experiments examined the effects of language characteristics on voice identification. In Experiment 1, monolingual English listeners identified bilinguals' voices much better when they spoke English than when they spoke German. The opposite outcome was found in Experiment 2, in which the listeners were monolingual in German. In Experiment 3, monolingual English listeners also showed better voice identification when bilinguals spoke a familiar language (English) than when they spoke an unfamiliar one (Spanish). However, English-Spanish bilinguals hearing the same voices showed a different pattern, with the English-Spanish difference being statistically eliminated. Finally, Experiment 4 demonstrated that, for English-dominant listeners, voice recognition deteriorates systematically as the passage being spoken is made less similar to English by rearranging words, rearranging syllables, and reversing normal text. Taken together, the four experiments confirm that language familiarity plays an important role in voice identification.
\end{abstract}

In this paper, we present four lines of evidence supporting the hypothesis that language familiarity plays a central role in voice recognition from memory when the speaker has no unusual vocal characteristics. There has been little investigation of the psychological factors in voice identification. To our knowledge, only three attempts have been made to evaluate the effect of accents or language familiarity on the ability to recognize voices (Goldstein, Knight, Bailis, \& Conover, 1981; McGehee, 1937; Thompson, 1987), and the usefulness of some of this research is limited. For example, design problems

\footnotetext{
- Experiment 2 was conducted while Gerhard Strube was at the Max Planck Institute for Psychological Research in Munich. We are grateful to the Bavarian Ministry of Education, as well as to teachers and parents, for allowing students to participate. Experiment 3 was supported in part by Grant RR08012, funded by the National Institute of Mental Health and the MBRS Program, Institute of General Medical Sciences, NIH. The assistance of Therese S. Ramirez and Cecilia Corral is gratefully acknowledged. Experiment 4 was funded in part by the Minority Access to Research Careers (MARC) Honors Program, NIH, and by Grant RR08012 from the MBRS Program, Institute of General Medical Sciences, NIH. This study was conducted by Liza Simental to fulfill the requirements for an honors project at the University of Texas at El Paso. We particularly appreciate Margaret Intons-Peterson's, Maria Sera's, and two anonymous reviewers' insightful comments on earlier drafts. Reprint requests should be sent to Judith P. Goggin, Department of Psychology, University of Texas at El Paso, El Paso, TX 79968-0553.
}

in the McGehee studies, including the confounding of conditions and voices, make those results uninterpretable (see Thompson, 1985b). The data reported by Goldstein et al. are somewhat more informative. However, their first two experiments used an immediate identification procedure more appropriate for those cases in which a voice sample is available than for cases in which identification is dependent on memory. Their third study compared Spanish-speaking voices with voices speaking heavily accented English and found no reliable differences, but there were no comparisons with voices speaking unaccented English. Thompson (1987) included all three conditions and found that monolingual English listeners identified English-speaking voices better than Spanish-speaking voices, with performance on accented voices falling between the other two conditions. The latter results serve as a starting point for the present research.

It seems self-evident that the cues for voice recognition arise from variations in the linguistic utterances of speakers. Because of this necessary relationship between voice and speech, it is reasonable to direct some attention to the identifying features of such utterances and to speculate about how these characteristics might affect a listener's ability to discriminate among speakers.

One obvious way in which messages may vary is in terms of dialect, language, or accent. Dialects are 
described as varieties of a language, which may differ in terms of grammar, lexicon, or phonology, and a language may be defined as a set of mutually intelligible dialects. However, there are exceptions to this rule, and most linguists concede that they cannot be defined in mutually exclusive ways (Chambers \& Trudgill, 1980). The distinction between a dialect and an accent is also ambiguous and tends to be one of degree rather than kind.

Traditional dialectology has focused on the distribution of single sounds or other linguistic features and the identification of geographical boundaries for the use of these features (i.e., isoglosses and bundles). This work has usually been descriptive rather than interpretive, but it is widely agreed that language and dialectical boundaries are gradual rather than abrupt (Francis, 1983). Even within a limited urban region, variations in language are typical. In one well-known study, for example, Labov (1972) examined linguistic change in a part of New York City. He based his conclusions primarily on quantitative measurement of phonological indices, although lexical and grammatical behavior were also noted. Variations, previously thought to be random, were found to be highly determined by social class, age, gender, and degree of formality. Many other studies (e.g., Milroy, 1986; Underwood, 1988) have confirmed that social and linguistic factors influence language variation.

Speech can also differ in voice quality, defined by Laver (1980) as "the characteristic auditory colouring of an individual speaker's voice" (p. 1) and described in terms of phonetic settings, such as nasality, creak, falsetto, or harshness. As Laver (1989) points out, settings vary in duration. Sometimes they last only briefly, for example, when conveying affect or other paralinguistic information. More interesting are quasipermanent settings, which can serve the extralinguistic purpose of identifying speakers by the phonetic components of voice quality. Laver's (1980) system describes voices in terms of their deviations from a neutral position on the basis of tension, supralaryngeal, and phonotory settings. Not only do voice settings differ because of people's individual vocal apparatus, but also normative settings may vary with language and dialect.

The tremendous variation in speech, not only among accents, dialects, and languages, but also among speakers" settings, complicates the task of the listener; however, communication can still occur for several reasons. First, because natural language is redundant, there is usually more than enough information to transmit a message. Francis (1983) suggests that variation in dialect and accent can be regarded as noise in the system, which may alter the surface form of utterances while preserving the underlying message. He argues that listeners can adapt to the language being heard by adjusting to different acoustic signals and phonological patterns, often without being aware of doing so.

There is also evidence (e.g., Labov, 1972) that members of a linguistic community share a set of normative speech patterns. On the basis of such observations,
Thompson (1987) argued that schemata for interpreting and storing voices are developed. He hypothesized that people acquire both "standard" schemata (e.g., for male and female voices) as well as specific modifications of those standard schemata to recognize particular individuals or identifiable groups (e.g., Southerners). This terminology is similar to that adopted by Woodworth (1938), who noted that regular figures are easily learned as instances of a schema; irregular figures, on the other hand, are described in terms of a "schema with correction" (p. 74). In the case of speech, such schemata would be composed of norms for all parts of language in which variation can occur, including the lexicon and grammar; however, because voice identification studies use standard passages, the characteristics of phonology and voice quality would be critically important.

Under this hypothesis, schemata are developed through personal experience, with the norms being learned by early adulthood even when speakers sometimes deviate from them in their own speech (Labov, 1972). Thus, one's "standard voice schema" will be based on the type of voices most frequently heard. Some characteristics of the schema may be invariable. For example, frequency differences between male and female voices are relatively constant, even when there are dialectical differences in overall pitch (Bartsch, 1987). However, an important part of the standard schema will be the norm for pronouncing words-and that may show conspicuous regional variation. Furthermore, our comprehension of spoken language depends on our ability to match the words we hear to our personal standard. Thus, although adjustment to new dialects typically occurs fairly readily as long as the differences are minor (Trudgill, 1983), it may be initially difficult to understand someone from another region who pronounces words in a way that does not fit our standard.

Voice identification involves matching a voice currently speaking to a remembered voice. If the voice is ordinary from the listener's perspective with no unusual quasipermanent settings (a voice we have dubbed a "vanilla" voice), then other aspects of the voice schema, such as deviations from standard pronunciation, may become more important. Of course, listeners are exposed daily to voices of people from their region and are experts at identifying small variations in their speech. However, that expertise may be inadequate when identifying someone speaking a different dialect or language, because their phonology may deviate so markedly from the standard accent that subtle distinctions are lost. The result is that, although a listener may easily distinguish among a set of speakers from his own region or even among speakers, each coming from a different region, there may be great difficulty in identifying a specific voice in a lineup of nonschema voices.

This hypothesis about the personal voice schema led us to predict a continuum of effects. Voices from the listener's region should be identified most accurately, but accuracy should decrease as the voices become more and more accented (from the point of view of the listener) and 
should be poorest when the voices are so accented as to be unintelligible. The effect of an unintelligible accent would also be produced when the voice is speaking a language that is unknown to the listener.

Initial experiments using bilingual speakers and monolingual listeners were consistent with this hypothesis. Monolingual English listeners recognized speakers much better when they spoke English than when they spoke Spanish (Thompson, 1987). Moreover, identification of the same voices speaking accented English was intermediate between the other two conditions. Although these data fit the predictions, the generalizability of this effect across language and type of listener is unknown. Experiments 1-3 were designed to address that issue and to explore the effects of language familiarity and accent on recognition. Experiment 4 focuses on the effects of different characteristics of a known language on voice recognition.

\section{EXPERIMENT 1}

If voice identification suffers when the listener does not understand the language being spoken, then this effect should generalize across languages. Thus, we can further test our hypothesis by attempting to replicate the original finding with a language other than Spanish. Experiment 1 provided that test by using monolingual English listeners and bilingual English-German speakers.

\section{Method}

Subjects. Sixty students at Kansas State University served as subjects (listeners) in the experiment in exchange for class credit. Most of these students had no prior exposure to German, but care was taken to exclude anyone who could understand spoken German. The subjects participated in groups ranging in size from 5 to 10 ; however, only the data for 5 subjects in each group were randomly selected for inclusion.

Materials and voices. The materials were two paragraphs, which had been used in the previous Spanish-English study and which were transiated into German by an experienced translator. The first passage, with 82 words in English and 93 words in German, consisted of statements one might hear during a bank robbery. The second passage, a paragraph about amnesia, contained 72 words in English and 77 words in German. All statements produced voice samples much longer than is necessary for optimum voice identification (cf. Clifford, 1980; Pollack, Pickett, \& Sumby, 1954).

The materials were recorded by 7 males who spoke both English and German fluently. These individuals spoke unaccented English (as heard by a Midwesterner), and in the experimenter's opinion, their voices had no clearly identifiable characteristics. Each speaker produced an English and a German version of the two passages. From this set of seven voices, six were arbitrarily selected for use in this study.

Experimental design and Procedure. The experimental design had one between-groups and one within-groups independent variable. The between-subjects factor was order of language judgment (English-German vs. German-English). The six voices were arbitrarily combined into three pairs. For each listener, one member of a pair served as the target for the English judgment and the other member was the target for the German judgment. Across subjects, each pair was used in both orders. The within-subjects factor was language (English vs. German). All six voices were used in the fi- nal lineup and always appeared in the same order; each voice appeared equally often as a target in each language condition.

The subjects were toid that they would hear a voice that they would later attempt to identify in a voice lineup. They then heard the first target voice reading the bank robbery passage in the language version to which they had been randomly assigned. After a 5 -min period (mostly filled with instructions), the subjects heard a lineup of six voices (including the target voice) reading the amnesia paragraph in the same language as the initial passage. The lineup was presented three times to ensure an adequate opportunity to evaluate the voices. Three presentations may be conservatively high, as the pilot subjects rarely requested more than two presentations. On the third time through, the subjects assigned a confidence rating to each voice as it was presented. The 6-point rating scale ranged from +3 (certain that this is the voice I heard originally) to -3 (certain that this is not the voice $I$ heard). Subsequently, the subjects were asked to make one of the following three responses as a final judgment: (1) NIL-the target voice is not in the lineup; (2) the target voice is Number $X$; or (3) NS-not sure which choice to make.

A few minutes later, the procedure was repeated for the second target voice. The second target voice and the subsequent lineup were in the other language (i.e., if German was used for the first test, English was used for the second test).

\section{Results}

Confidence ratings and correct identifications of the target voice were separately analyzed. Analyses were not performed on the errors; however, the means for those categories are reported.

Confidence-rating data. The subjects were better able to identify voices when they were speaking a familiar language than when they were speaking an unfamiliar language. This effect of language was confirmed by an analysis of the confidence ratings for the target voices (see Table 1). The subjects assigned higher confidence ratings

Table 1

Mean Confidence Ratings of Targets and Lures and Group d' Values, Experiments 1-4

\begin{tabular}{|c|c|c|c|c|}
\hline \multirow{2}{*}{$\begin{array}{c}\text { Listeners' } \\
\text { Language(s) }\end{array}$} & \multirow{2}{*}{$\begin{array}{c}\text { Speaker's } \\
\text { Text }\end{array}$} & \multicolumn{2}{|c|}{ Confidence Rating } & \multirow{2}{*}{$\begin{array}{c}\text { Group } \\
d^{\prime}\end{array}$} \\
\hline & & Targets & Lures & \\
\hline \multicolumn{5}{|c|}{ Experiment 1} \\
\hline English & $\begin{array}{l}\text { English } \\
\text { German }\end{array}$ & $\begin{array}{r}.88 \\
-.28\end{array}$ & $\begin{array}{l}-1.50 \\
-1.30\end{array}$ & $\begin{array}{r}1.19 \\
.58\end{array}$ \\
\hline \multicolumn{5}{|c|}{ Experiment 2} \\
\hline German & $\begin{array}{l}\text { English } \\
\text { German }\end{array}$ & $\begin{array}{r}-.12 \\
1.36\end{array}$ & $\begin{array}{l}-1.54 \\
-1.55\end{array}$ & $\begin{array}{r}.73 \\
1.47\end{array}$ \\
\hline \multicolumn{5}{|c|}{ Experiment 3} \\
\hline English & $\begin{array}{l}\text { English } \\
\text { Accented English } \\
\text { Spanish }\end{array}$ & $\begin{array}{r}.80 \\
.10 \\
-.35\end{array}$ & $\begin{array}{l}-1.86 \\
-1.85 \\
-1.56\end{array}$ & $\begin{array}{r}1.34 \\
.95 \\
.72\end{array}$ \\
\hline Spanish/English & $\begin{array}{l}\text { English } \\
\text { Accented English } \\
\text { Spanish }\end{array}$ & $\begin{array}{l}.62 \\
.23 \\
.78\end{array}$ & $\begin{array}{l}-1.81 \\
-1.76 \\
-1.94\end{array}$ & $\begin{array}{l}1.22 \\
1.05 \\
1.34\end{array}$ \\
\hline \multicolumn{5}{|c|}{ Experiment 4} \\
\hline English dominant & $\begin{array}{l}\text { Text } \\
\text { Mixed words } \\
\text { Mixed syllables } \\
\text { Reversed text } \\
\end{array}$ & $\begin{array}{r}1.10 \\
.58 \\
.15 \\
-.77 \\
\end{array}$ & $\begin{array}{l}-1.71 \\
-1.68 \\
-1.64 \\
-1.37 \\
\end{array}$ & $\begin{array}{r}1.40 \\
1.22 \\
.68 \\
.38 \\
\end{array}$ \\
\hline
\end{tabular}

Note-Confidence ratings: $+3=$ certain that this is the voice $I$ heard; -3 = certain that this is not the voice I heard. 
to the target voices in the English condition than to the same target voices in the German condition $[F(1,58)=$ $10.71, p<.01]$. There was no reliable effect of language order, nor was the interaction reliable. The mean confidence ratings assigned to the five lure voices were also analyzed. None of the sources in that analysis of variance (ANOVA) was reliable (all $F \mathrm{~s}<1.1$ ).

Because each subject made a single response to each voice in each language, only one of which was the target, there is no way to calculate the individual subject's probability of both hits and false alarms necessary for a signal-detection analysis; that is, the probability of a hit for each language could only be 0 or 1.0 . However, group $d^{\prime}$ values were estimated by summing the frequencies of each rating across all subjects and estimating the $d^{\prime}$ for each of the five points on the group receiver-operating characteristics (ROC) curve (cf. Anderson \& Borkowski, 1978). The group $d^{\prime}$ values (see Table 1) are the means of these five estimates and corroborate that voice recognition is better when the voices speak a familiar language.

Identification data. The identification data, which appear in Table 2, also showed a clear effect of language. Correct identifications were reliably higher for English than for German $[F(1,58)=13.85, p<.001]$. Consistent with the confidence-rating results, there was no reliable order $\times$ language interaction, but the main effect of order did approach significance $[F(1,58)=3.99$, $p<.10$ ]. Overall correct identification was marginally higher when the first language heard was German $(M=$ .33) compared with when it was English $(M=.18)$.

As Table 2 shows, the rate of incorrect identification of lures was lower for English voices than for German voices. Consistent with the group $d^{\prime}$ values, these data fail to support a criterion-shift explanation of the correct identification data. Such an interpretation would require more incorrect identifications of English lures than German lures, whereas the means were in the opposite direction. The overall rate of not in lineup (NIL) responses was low for both languages. Finally, more not sure (NS) responses were given when the first language heard was English $(M=.52)$ than when it was German $(M=.28)$.

To determine whether the subjects' confidence ratings for correct identifications differed from those for incorrect identification of lures, mean confidence ratings were calculated. No analysis was performed, however, because these means ( 2.65 and 2.68 , respectively) obviously did not differ.

\section{Discussion}

Monolingual English listeners identify voices speaking English better than the same voices speaking German. This result replicates the outcome with Spanish (Thompson, 1987). It is unlikely that these two quite different languages both somehow constrain speech in a way that makes voice recognition difficult. Thus, the present data, taken together with the previous results with Spanish, strongly support the hypothesis that language familiarity plays an important role in identifying voices.

Although the point is tangential to these experiments, it is interesting to note that the subjects were equally confident in their choice whether they correctly identified the target voice or incorrectly identified a lure. Other research has consistently found an extremely modest, but positive, correlation between confidence and accuracy of voice

Table 2

Proportion Correct and Incorrect Identifications, Experiments 1-4

\begin{tabular}{|c|c|c|c|c|c|}
\hline \multirow{2}{*}{$\begin{array}{c}\text { Listeners } \\
\text { Language(s) }\end{array}$} & \multirow{2}{*}{$\begin{array}{c}\text { Speakers } \\
\text { Text }\end{array}$} & \multicolumn{2}{|c|}{ Identification } & \multirow[b]{2}{*}{ NIL } & \multirow[b]{2}{*}{ NS } \\
\hline & & Correct & Incorrect & & \\
\hline \multicolumn{6}{|c|}{ Experiment 1} \\
\hline \multirow[t]{2}{*}{ English } & English & .40 & .15 & .08 & .35 \\
\hline & German & 12 & .25 & .18 & .45 \\
\hline \multicolumn{6}{|c|}{ Experiment 2} \\
\hline \multirow[t]{2}{*}{ German } & English & .35 & .52 & .13 & .02 \\
\hline & German & .57 & .36 & .01 & .07 \\
\hline \multicolumn{6}{|c|}{ Experiment 3} \\
\hline English & English & .57 & .32 & .02 & .10 \\
\hline & Accented English & 40 & 35 & .08 & .17 \\
\hline & Spanish & 28 & .38 & .13 & .20 \\
\hline Spanish/English & English & 35 & .23 & .13 & .28 \\
\hline & Accented English & .42 & .25 & .17 & .17 \\
\hline & Spanish & 48 & .18 & .08 & .25 \\
\hline \multicolumn{6}{|c|}{ Experiment 4} \\
\hline English dominant & Text & .62 & .32 & .03 & .03 \\
\hline & Mixed words & .48 & .37 & .07 & .08 \\
\hline & Mixed syllables & .37 & .48 & .07 & .08 \\
\hline & Reversed text & .30 & .55 & .12 & .03 \\
\hline
\end{tabular}

Note-NIL $=$ not in lineup; NS $=$ not sure. 
identification (Clifford, 1980; Deffenbacher, 1985; Saslove \& Yarmey, 1980). These data show no relationship at all.

\section{EXPERIMENT 2}

If our view of the relationship between language familiarity and voice identification is correct, there should be superior voice identification performance with Germanspeaking voices than with English-speaking voices if the listeners understand German but do not understand English. To evaluate this hypothesis, we arranged to test German nationals who do not speak English.

\section{Method}

Subjects. In western Germany, virtually all college students command a good working knowledge of English. In order to find native speakers who do not know English, fifth- and sixth-grade students were recruited from certain schools ("Humanistisches Gymnasium") where foreign-language learning starts with Latin instead of English. Fourteen classrooms from six schools in Munich participated in the study. The analysis excluded 27 subjects whose self-rating of language abilities indicated that they either were not native speakers of German or already had some knowledge of English. In all, data from 337 subjects were collected and analyzed. The subjects participated in classrooms with group size varying from 11 to 38 , with a mean of 24 students.

Materials. The recordings were copies of the amnesia and bankrobbery statements used in Experiment 1 , except that in this case all seven voices were used to permit target-absent lineups. Although the Kansas State speakers making these recordings knew German, their German pronunciation sounded heavily accented, sometimes funny, and at times incorrect to the German listeners.

Experimental design and Procedure. Each classroom was presented with one speaker-language combination and with a sixvoice lineup in the same language. In contrast to Experiment 1, not all groups had the target voice in the lineup.

The experimental sessions took place in the classroom during the time allocated to a regular lesson (45 min). The students were first introduced to the practical importance of voice recognition. They were also told that the speaker might be talking in an unknown language and that they were going to listen to several voices at the end of the session to determine whether the present speaker was among them. They then heard a tape recording of the bank-robbery passage, spoken either in English or in German by 1 of the 7 speakers according to the condition to which they had been randomly assigned.

Language fluency was next assessed by eight otherwise identical rating scales on which subjects indicated their ability to read, write, speak, and understand spoken English and German. Each 5-point scale ranged from 1 (excellent) to 5 (not at all). Mean scores per language could therefore range from 1 (excellent in all respects) to 5 (total ignorance of the language). To be included as a monolingual German, a subject's mean rating in German could not exceed 1.5 and the mean rating in English had to be 4.0 or higher.

The subjects were then given instructions for the test, which was identical to the lineup in Experiment 1. They had to listen twice to the six voices in the lineup, listen to them a third time while giving confidence ratings, and then make a final judgment of Nein (NII, not in lineup), Sprecher Nr. $X$ (the target voice is Number $X$ ), or Unsicher (NS, not sure which choice to make). Language-skill ratings and test instructions created an interval of about $25 \mathrm{~min}$ between presentation of the target voice and the initiation of the first lineup.

\section{Results}

Confidence ratings and correct identifications of the target voice were separately analyzed. Except where noted, the target-absent conditions were omitted. These data did not yield any additional information and were excluded to facilitate comparisons across experiments. Mean errors in identification are reported; however, these data were again not analyzed because of their lack of independence.

Confidence-rating data. As shown in Table 1, the subjects responded to the target with much greater confidence when the speaker spoke German than when the speaker spoke English, just the reverse of what was found in Experiment 1 with English monolingual subjects. This difference was reliable $[F(1,294)=30.95, p<.001]$. Confidence ratings of lures were clearly not affected by the language of the speaker.

Group $d^{\prime}$ values (see Table 1) were calculated in the same way as described in Experiment 1. These values confirm the outcome for the confidence ratings of targets, with recognition of voices speaking a familiar language (German) being almost twice as good as recognition of voices speaking an unfamiliar language (English).

Identification data. The identification data from conditions in which the target was present in the lineup are displayed in Table 2 and show that the effect of language was the reverse of that found in Experiment 1. Overall, listeners could identify the voices significantly better when they were speaking German than when they were speaking English $[F(1,294)=14.72, p<.001]$.

The mean incorrect identification rate was higher for English than for German. Once again, the means are in the opposite direction to that required for a criterion-shift interpretation. The proportions of NIL and NS responses were quite low. It should be noted that, when the target voice was absent from the lineup, the rates for incorrect identification of lures reached mean values of .95 for both English and German. This indicates that most subjects were convinced that the target voice had to be present in the lineup when, in fact, it was not.

To determine whether the confidence ratings for correct identifications differed from those for incorrect identifications of lures, an unweighted-means ANOVA was performed on these ratings collapsed over voices. The confidence ratings for correct identifications $(M=2.66)$ did not differ from those for incorrect identifications $(M$ $=2.59)(F<1)$. As in the correct-identification analysis, the subjects were more confident identifying voices speaking German $(M=2.72)$ than voices speaking English $(M=2.52)[F(1,260)=3.80, p=.052]$.

\section{Discussion}

Monolingual German listeners identify voices speaking English worse than the same voices speaking German. In contrast, Experiment 1, using the same recordings, found that monolingual English listeners identify voices speaking English better than the same voices speaking German. In short, the very same voice recordings lead 
to better or worse identification depending on whether or not the listener can understand the language. This result complements nicely the results of Thompson (1987). It rules out the possibility that the superiority of English with U.S. listeners reported in that study could be due to properties of the language itself.

\section{EXPERIMENT 3}

As a working hypothesis, it seems reasonable to suppose that lack of language familiarity produced the inferior identification of voices speaking a foreign language in Experiments 1 and 2 , as well as the inferior identification shown earlier with Spanish voices (Thompson, 1987). If familiarity is a critical factor, then bilingual subjects should be equally adept at recognizing voices speaking either of their two languages. The present experiment tests that prediction by using subjects who are bilingual in Spanish and English.

\section{Method}

Subjects. A total of 567 students at the University of Texas at El Paso participated in the study. Of these, 39 were excluded for misunderstanding the directions or because they were foreign students whose first language was neither English nor Spanish. From the remaining subjects, data were analyzed for 360,180 of whom were Spanish-English bilinguals and 180 of whom were nearly monolingual in English. These subjects were chosen by three judges on the basis of biographical information and language self-ratings. The English subjects had the least knowledge of Spanish, but the highest farniliarity with English, and for convenience, they will hereafter be labeled "monolingual." The bilinguals were those judged to be the most competent in both English and Spanish.

Materials. The biographical questionnaire gathered information about the subject's ethnicity, language-learning experience, and language usage. In addition, the subjects were asked to rate their skills in reading, writing, speaking, and listening to both Spanish and English. Each skill in each language was rated on a 5-point Likert scale ranging from 1 for very poor or no ability to 5 for excellent ability. The subject's overall rating in each language was the mean of the four ratings.

The materials consisted of the two English statements from Experiment 1 (bank robbery, amnesia) and their Spanish translations. The first passage contained 76 words in Spanish, and the second passage was 71 words long in Spanish.

The statements were tape recorded in Kansas by six males who spoke both English and Spanish. These voices had been used by Thompson (1987) and had no clearly identifiable characteristics from his perspective. Neither the English nor the Spanish accents were typical of this U.S.-Mexico border region, but the messages were completely understandable to the subjects. Each speaker taped an English, a Spanish, and a heavily accented English version of each passage. To obtain a consistent accent condition, a volunteer taped an English version using a strong Spanish accent, and the speakers tried to duplicate that accent. Accented dialects produced in this fashion may not be perfect, with errors of hypercorrection being typical (Trudgill, 1983); however, a similar procedure has been previously used successfully, such as in the "matched guise technique" (e.g., Lambert, 1967), and seemed preferable to confounding speakers with language condition.

Experimental design and Procedure. The design was a $2 \times$ $3 \times 6$ factorial with two subject groups (monolingual, bilingual) crossed with three language conditions (Spanish, English, accent) and six voices. All voices were used in the final lineup, with each voice serving equally often as a target in each language condition.

The subjects participated in groups ranging in size from 2 to 18. Each group heard one of the 18 possible combinations of target voice and language condition. Inasmuch as the subjects were not identified as monolingual or bilingual prior to testing, the groups contained some random mixture of the two types of subjects. Additional groups were tested, as needed, to obtain 10 monolingual and 10 bilingual subjects in each voice-language combination

The subjects first heard the target voice read the bank-robbery passage. They were instructed to listen carefully because they would later hear a lineup of six voices. A 30 -min retention interval then began. During this interval, the subjects completed the biographical questionnaire, rated their language skills, and spent the rest of the time in conversation. The subjects next heard the lineup of six voices, including the target voice, reading the amnesia paragraph in the same language condition (i.e., English. Spanish, or accent) as the initial passage. The testing procedure was identical to that in Experiment 1.

\section{Results}

Subjects. Group assignment was primarily based on the subjects' language ratings. The mean self-ratings in English placed both the monolinguals (4.61) and the bilinguals (4.23) between above average and excellent on the 5 -point scale. This difference, while not large, was reliable $[r(358)=5.45, p<.001]$. The discrepancy in Spanish ratings was more pronounced and was also significant $[t(358)=37.73, p<.001]$. The mean rating for the monolingual subjects $(1.12)$ indicated that they had little or no knowledge of Spanish, whereas the bilinguals' mean Spanish rating (3.69) was somewhat better than average.

The biographical data were consistent with these ratings. Most of the bilinguals had Hispanic parents, whereas most of the monolinguals had non-Hispanic parents. About one-third of the bilinguals, but none of the monolinguals, had lived in a Hispanic country. The subjects' language history also differed. Almost all of the monolinguals had learned English first. For the bilinguals, the first language tended to be Spanish, but a sizable fraction of these subjects had acquired the two languages simultaneously or had learned English first.

Confidence-rating data. Mean confidence ratings of target and lure voices and group $d^{\prime}$ values appear in Table 1 . The confidence ratings of the targets were, with one exception, positive, but none was high. The English monolinguals were much more confident when the speaker's text was in English than when it was in Spanish; accented text produced intermediate ratings. The bilinguals' confidence ratings, on the other hand, were somewhat higher when the voice spoke Spanish than when it spoke English, and were lowest for accented English. An ANOVA confirmed these results. Confidence ratings of monolinguals and bilinguals did not differ $[F(1,324)$ $=2.82, p>.05]$, nor was there an effect of language $[F(2,324)=2.59, p>.05]$. However, subject group did interact with language condition $[F(2,324)=3.41$, $p<.05$ ]. In agreement with previous results (Thompson, 1985a, 1985b, 1987), the voices were not equally 
identifiable $[F(5,324)=14.13, p<.001]$. The language $X$ voice interaction was also reliable $[F(10,324)=2.32$, $p<.05]$; across voices, confidence ratings varied less when English was spoken than when either accented English or Spanish was spoken.

The mean confidence ratings of the voices when they served as lures were also analyzed. The main effect of neither subject group nor language condition was significant $(F \mathrm{~S}<1)$, but the effect of voice was again reliable $[F(5,324)=3.95, p<.01]$. The only significant interaction was that between voice and language $[F(10,324)$ $=2.64, p<.01]$. Once again, across voices, confidence ratings were more similar when English was spoken than in the other two language conditions.

Group $d^{\prime}$ values were estimated using the procedure adopted in Experiment 1. The pattern of these estimates differs for the monolingual and bilingual subjects and corresponds to that shown by the confidence ratings of targets. The monolinguals recognized the voices speaking English better than the same voices speaking Spanish, with accented voices intermediate. The bilinguals were much less affected by language; identification of voices speaking accented English was somewhat poorer than identification of voices speaking either English or Spanish, which differed little.

Identification data. Correct identifications of the target voices and three kinds of errors were tallied for each subject group and language condition (see Table 2). There was no overall difference between monolinguals and bilinguals in correct responses. Slightly more correct responses were made when the language was English than when it was either accented English or Spanish, but there was no main effect of language $(F<1)$. However, subject group did interact with language condition $[F(2,324)=6.14$, $p<.01]$. In addition, voice was again a significant factor $[F(5,324)=8.23, p<.01]$, and the language $\times$ voice interaction was reliable $[F(10,324)=1.92$, $p<.05]$.

The pattern of results for the monolinguals was consistent with the confidence-rating data. Correct identification was highest with English voices, lowest with Spanish voices, and intermediate with accented voices. An ANOVA of the monolingual data confirmed that these differences, similar to those found by Thompson (1987), were significant $[F(2,162)=5.78, p<.05]$. The outcome for the bilinguals, on the other hand, differed somewhat from the confidence-rating data. Correct identification was highest for Spanish, but the order of the other two language conditions was reversed, with accented voices being correctly identified more often than English voices. Thus, the ordering of correct identifications for the bilingual subjects was the reverse of that for the monolinguals. In addition, whereas the analysis of the monolinguals' data indicated that language had a significant effect, analysis of the bilinguals' correct identifications showed no effect of language condition $[F(2,162)$ $=1.24, p>.05]$.

As noted earlier, error data were not analyzed because they are not independent of correct responses. However, because the subject groups made the same number of correct identifications, the distribution of errors across categories is of interest. The bilinguals were equally likely to choose an incorrect voice $(M=.22)$ as to say they were not sure $(M=.23)$. In contrast, the monolinguals were about twice as likely to identify a lure incorrectly $(M=$ .35 ) as to be unsure (NS) of which voice was the target $(M=.16)$. The higher rate of incorrect identification of lures by the monolinguals occurred in all language conditions. Thus, these data do not support a criterion-shift interpretation of the differences in correct identifications. In fact, the $d^{\prime}$ values (see Table 1) show the same trends as those found for the confidence ratings and correct identifications. The subjects in both groups rarely said that the target voice was not in the lineup (NIL), but this type of error was more common for the bilinguals $(M=.13)$ than for the monolinguals $(M=.08)$. NIL responses were least probable with the English voices for the monolinguals and with the Spanish voices for the bilinguals.

To determine whether the confidence ratings for correct identifications differed from those for incorrect identification of lures, an unweighted-means ANOVA was performed on these data collapsed over voices. There was no overall difference in confidence ratings for correct and incorrect identifications and no effect of language (both $F$ s $<1)$. However, the bilinguals $(M=2.51)$ were more confident of their responses than the monolinguals $(M=$ 2.19) $[F(1,241)=11.60, p<.01]$. Subject group also interacted with language condition $[F(2,241)=3.63$, $p<.05]$. The bilinguals' ratings were only slightly affected by language, with the mean ratings for the English (2.57), accent (2.40), and Spanish (2.58) conditions being approximately equal. In contrast, the monolinguals' ratings varied with language, and in particular, the mean confidence rating for Spanish (1.92) was lower than that for either English (2.24) or accented English (2.36).

\section{Discussion}

The distinctive patterns of results for monolingual English listeners and bilingual Spanish-English listeners strongly support the hypothesis that language familiarity is important in voice recognition. The data for the monolinguals replicated the outcome in Kansas (Thompson, 1987). Confidence ratings of targets were higher when the voices spoke English than when they spoke Spanish, with voices speaking accented English producing intermediate ratings. A different pattern of results emerged with bilingual listeners. Confidence ratings were somewhat higher for voices speaking Spanish than for voices speaking English, but the difference was small. The bilinguals were considerably less confident in their ratings of accented voices. The identification data produced essentially the same results.

If language familiarity does indeed play an essential role in voice identification, the pattern of results found in this experiment would be predicted. Voice recognition should be good when the listener understands the language and poor when the language is not understood. If the listener is a fluent bilingual, performance should be approximately 
equal in both languages. However, unusual accents can have a negative effect on voice identification. The confidence-rating data showed that the accented-English condition produced the lowest confidence ratings for the bilingual listeners and produced intermediate ratings for the monolingual listeners.

\section{EXPERIMENT 4}

The first three experiments all lead to the same conclusion: Voice recognition is more accurate when the subject is familiar with the language being spoken. The design of these studies, however, does not permit identification of the factors associated with language familiarity that lead to this facilitation. In Experiments 1 and 2, the subjects either did or did not understand the passages, but comprehension was based on familiarity with a mixture of cues from the language's phonology, lexicon, and syntax. A similar situation existed in Experiment 3, except that an accented English condition was also included. Because these passages preserved English syntax and lexicon, the lowered performance suggests that familiar phonological cues are at least one important contributor to voice recognition.

The present experiment was undertaken as an initial attempt to disentangle the effects of the various possible sources of familiarity on voice identification. In the same type of voice-recognition situation as used previously, the subjects heard passages of regular English text or one of three corruptions of this text: (1) mixed words, which produced passages that were semantically anomalous, but in which some of the syntax and all of the lexicon were preserved; (2) mixed syllables, in which normal phonology is retained; and (3) reversed text, in which normal phonological cues are destroyed. In the latter two cases, most of the usual semantic, syntactic, and lexical cues are absent.

\section{Method}

Subjects. The subjects were 335 students at the University of Texas at El Paso. Of these, 5 foreign students whose first language was neither English nor Spanish were eliminated, 18 were excluded for misunderstanding the directions, and 46 were eliminated for rating their proficiency in Spanish equal to or higher than that in English. From the remaining subjects, data were analyzed for 240 individuals, excess subjects in each group being eliminated by two judges. This elimination, carried out prior to an examination of the recognition data, was based on weak English-proficiency ratings relative to the Spanish-proficiency ratings, Spanish being spoken by parents, and Spanish being spoken frequently by the subject. An additional 30 students from the same pool served as pilot subjects to select stimulus voices.

Materials. The same biographical questionnaire and self-rating scales used in Experiment 3 were employed to determine English and Spanish fluency. Stimulus materials again were two paragraphs. One paragraph was the bank-robbery passage used in previous experiments; the second paragraph concerned playing the clarinet and was of approximately the same length.

There were four versions of these paragraphs, three of which were taped directly by male speakers. The first version (text) used the original paragraphs and served as a control condition. The second version (mixed words) contained all the words from the text, but the words were jumbled to produce nonsense paragraphs. For example, one sentence was, "Move panic and the door can't floor." The third version (mixed syllables) used syllables from the original passages to make nonsense words, such as "A ribrates is a roodside mulamped." There was still some semblance of sentence structure and sentence flow because all one-syllable words were retained. The fourth version of the two paragraphs (reversed text) was obtained by reversing the text versions by means of a reel-to-reel recording device.

The recordings were made by eight males who spoke English fluently. The experimenter judged their voices to be both unaccentod and without idiosyncrasy. Each speaker was asked to review the passages until he felt comfortable reading them and then practiced speaking into the microphone until he was able to say each version of the paragraphs without error

From this pool of eight voices, the two voices that were most easily identified were excluded. This was accomplished by randomly assigning 30 pilot subjects to listen to the text, mixed-words, or mixed-syllables version. These subjects heard the lineups twice; on the second repetition, they were instructed to make note of voices that had identifiable cues. The two voices that were most frequently listed by the subjects were eliminated.

Experimental design and Procedure. The $4 \times 6$ factorial design crossed the four versions of the passages (text, mixed words, mixed syllables, and reversed text) with the six voices. All six voices were used in the lineup, and each voice appeared equally often as a target in each condition.

The subjects participated in groups ranging from 1 to 10 . Groups were combined until there was a minimum of 10 English-dominant subjects in each of the 24 version-voice combinations. Groups were randomly assigned to hear one of these combinations. The version of the passages was the same for both target and lineup; for example, if the target was Voice 3 reading the mixed-syllables bankrobbery passage, the voices in the lineup read the mixed-syllables clarinet passage.

The subjects were told that they would hear a voice that they were to try to identify later in a voice lineup. They first heard a tape recording of the target voice reading the assigned version of the robbery passage, followed by a 9-min retention interval, during which time they completed the biographical questionnaire. The subjects then heard all six voices reading the clarinet passage. The voices in the lineup were always in the same order so that the target's location in the lineup was balanced across subjects. Except for the fact that the lineup was presented only twice, the test procedure was the same as in Experiments 1 and 3; the subjects just listened to the voices during the first presentation, and during the second presentation, they judged their confidence that each voice was or was not the target voice. The subjects then made a final judgment.

\section{Results}

Subjects. Because this study was conducted on the U.S.-Mexico border where bilingualism is prevalent, care was taken to ascertain the subjects' dominance in English. This was viewed as important to ensure their sensitivity to the main independent variable, which was related to characteristics of the English language. The biographical data indicated that many of the subjects were bilingual, as anticipated, but $67 \%$ had learned English first, and both parents spoke English in almost three-quarters of the cases.

More important are the proficiency ratings, which have been shown to be good measures of language ability (Lemmon \& Goggin, 1989; Macnamara, 1969). The mean selfrating in English (4.41) placed the subjects between above 
average and excellent, and the mean self-rating in Spanish (2.19) placed them between very poor and below average ability. An ANOVA confirmed that this difference between English and Spanish ratings was reliable $[F(1,216)=1001.44, p<.001]$. There were no differences in proficiency ratings among either the four text conditions $(F<1)$ or the six target-voice conditions $[F$ $(5,216)=1.55, p>.05]$, and none of the interactions was significant $(F \mathrm{~s}<1.22)$.

Confidence-rating data. Mean confidence ratings of the targets for each version of the passages are shown in Table 1. Confidence in identifying the target voice is clearly related to condition. The more similar the passage is to English, the higher the confidence rating. An ANOVA confirmed that condition did affect the confidence ratings $[F(3,216)=7,42, p<.001]$. Scheffé tests indicated that, of the adjacent groups, only the difference between the mixed-syllable and reversed-text versions approached significance $[F(1,216)=4.98, p<.10]$; however, nonadjacent means differed reliably $(p s<.05)$. There was no effect of target voice and no interaction between text condition and voice $(F \mathrm{~s}<1)$.

Mean confidence ratings of lures (see Table 1) vary little, and an ANOVA revealed no effect of text condition $[F(3,216)=1.99]$ or of voice $[F(5,216)=1.86$, both ps $>.05]$. There was, however, a reliable text $\times$ voice interaction $[F(15,216)=1.92, p<.05]$. This interaction is difficult to interpret, but text condition appeared to have a greater influence on the confidence ratings for Voice 1 than for the other voices.

Mean $d^{\prime}$ values for each group were also calculated according to the procedure used in previous experiments and appear in Table 1. It can be seen that these means decrease as the passages were made increasingly discrepant from English, confirming the relationship shown by the confidence ratings.

Identification data. Table 2 displays the proportion of correct responses and the various kinds of errors from the final judgment task. Correct responses decreased as the passages became progressively more incomprehensible; correct identifications of voices speaking text were more than twice as great as for reversed text, with mixed words and mixed syllables intermediate. These differences in correct responses were, of course, mirrored by differences in identification error rates. The analysis confirmed that text condition affected correct responses $[F(3,216)$ $=5.08, p<.01]$, whereas voice and the condition $\times$ voice interaction were nonsignificant sources of variance $[F(5,216)=1.56, p>.05$ and $F(15,216)=1.32$, $p>.05$, respectively]. Scheffé tests indicated that, although adjacent text conditions did not differ reliably, nonadjacent conditions did differ $(p s<.05)$.

To assess whether the subjects' confidence judgments depended on whether their responses were correct, an unweighted-means ANOVA was performed on the confidence ratings for correct responses and for incorrect identification of lures. Confidence ratings were somewhat higher for correct responses $(M=2.42)$ than for incor- rect responses $(M=2.22)$, but this difference was not significant $[F(1,201)=2.43, p>.05]$, and no other sources of variation were reliable $(F \mathrm{~s}<1.0)$.

\section{Discussion}

The purpose of the present experiment was to examine the effects of language familiarity on voice recognition by varying the characteristics of a known language. It was, consequently, important to ascertain that the listeners were competent in English. Despite the fact that many subjects were bilingual, biographical responses and self-ratings of language skills indicate that the procedures used to restrict participation to those strongly dominant in English were successful. Further evidence is provided by noting similarities across experiments, although such comparisons are somewhat problematical because of differences in subjects, voices, passages used in the lineups, and retention intervals; nevertheless, voice recognition with regular text was reasonably comparable to that found in the first three studies with monolingual subjects.

The most interesting outcome of this experiment, however, is the voice recognition performance under the mixed-word, mixed-syllable, and reversed-text conditions. As the passages were made more remote from English, voice recognition systematically deteriorated, with performance in the reversed-text condition being, if anything, worse than what was previously found with a foreign language. These data indicate that voice recognition is facilitated when the listener comprehends the message and that recognition decreases as the syntactic, semantic, and phonological characteristics of the message become less familiar.

\section{GENERAL DISCUSSION}

In his discussion of the semiotic role of speech, Laver (1989) distinguishes between two communication functions carried by speech-its symbolic function and its evidential function. The former deals with the form of language, which consists of the phonological and grammatical characteristics on which the semantic level of language is based. The latter concerns the medium of communication, or how the message is realized in the speaker's verbalizations. Although it is important that the medium conveys the semantic meaning of the message, this aspect also marks the individual speaker's identity.

The present data, by clearly establishing the critical role of language familiarity in voice identification, argue for an interdependence between the symbolic and evidential functions of language. The first three experiments show that confidence in voice identification is increased approximately twofold when the listener understands the language relative to when the message is in a foreign language. In addition, these data suggest that identification of voices involves more than mere comprehension. When strongly accented speech was used, the accented voices produced identification intermediate betweęn unaccented (from the point of view of the listener) and unintelligible 
speech. This is the same result found in earlier research (Thompson, 1987). The outcome of the final experiment confirms that, as the message being heard is increasingly distorted through the loss of familiar language cues, recognition of the speaker's voice becomes more and more difficult. Thus, the present experiments converge on the conclusion that message composition affects voice recognition. What is not so clear is the reason for this relationship, but several alternatives can be proposed.

One alternative is that listeners use schemata for identifying voices. Initially, we proposed that these schemata were language based and consisted of norms for all aspects of a language, including its syntax, lexicon, and phonology. Such schemata, learned through exposure to voices in a local area, would enable the listener to identify regional speakers by noting deviations from these norms. This hypothesis leads to the prediction that voice identification would vary as a function of the similarity between the listener's and speaker's dialects. That is, people should be adept at identifying variations in the local speech patterns; however, when the speaker's dialect deviates markedly from that of the listener, subtle distinctions would be missed, leading to difficulty in identifying a specific speaker in a group of speakers using an unfamiliar dialect. As a consequence, voice-identification accuracy should decrease as deviations from the listener's language norms increase and should be seriously impaired with speakers of a foreign language.

Data from Experiments $1-3$ and from Thompson (1987), in which language varied, can be explained in terms of language schemata. However, the results of Experiment 4 are more difficult to interpret within this framework. Deviations from language norms can, of course, be produced by mixing words and syllables because of the effects of context on phonology. Nevertheless, it is widely agreed that humans are remarkably able to maintain perceptual constancy by making corrections to variations in the speech event, such as occurred in this study.

If the schemata used for voice identification are not based on language norms, on what else could they depend? Another alternative, and one that is consistent with the results of all these studies, is that the schemata are speaker based. ${ }^{1}$ Data from several recent experiments suggest that there is some reciprocity between speaker identity and item perception. For example, in one line of research, Mullennix, Pisoni, and Martin (1989) presented lists of words that had been read by one talker or by several talkers and asked subjects to identify the words under various conditions. Their results showed that recognition of spoken words was better in the single-talker condition than in the multiple-talker condition. Using a different paradigm, Johnson (1990) presented words either in isolation or embedded in carrier phrases and varied perceived speaker identity by manipulating the fundamental frequency $(F 0)$ of the carrier phrases. When perceived speaker differences in the carrier phrases were minimized, the effect of differences in the test items' fundamental frequencies was also reduced; likewise, enhanced differences in the perceived speakers produced a corresponding shift in identification of test words with virtually identical $F 0$ s. Both Mullennix et al. (1989) and Johnson (1990) conclude that characteristics of the speaker's voice play an important role in the perceptual normalization of speech.

The aforementioned line of investigation has focused on the effect of the speaker's voice on the perception of speech items, whereas the present research is concerned with the reverse-the effect of the characteristics of the speech items on identification of the speaker's voice. Nearey (1989), however, has suggested that there is a cyclic process involved in speaker normalization in that information about the speaker is used to identify words and word pronunciation is, in turn, used to make inferences about the speaker. If this cycle is interfered with, as would be the case in Experiment 4 when the material is corrupted, it seems likely that voice identification would suffer. The same effect should also occur when a foreign language or heavily accented voice is used, because of the subject's lack of familiarity with the different phonological systems (cf. Disner, 1980).

An alternative, but not necessarily incompatible, explanation of the relationship between the form of the message and voice recognition can be based on attentional considerations. If it is assumed that listeners automatically attempt to process messages heard, even when attention is focused on recognizing the speaker's voice and not on message content, then nonstandard messages may increase the load on the processing capacity of the listener and may lessen the capacity for processing cues to the speaker's voice. The data of the present experiments do not distinguish between these two explanations.

Finally, although not central to the focus of this research, it is important to note that all four experiments showed that the subjects were equally confident in their choices whether they correctly identified the target voice or incorrectly identified a lure. We used direct analytic comparisons rather than computing correlations; however, our data are consistent with other research that has typically found only an extremely modest positive correlation between confidence and accuracy of voice identification (Clifford, 1980; Deffenbacher, 1985; Saslove \& Yarmey, 1980). Aithough the absence of a relationship is difficult, if not impossible, to prove, this outcome suggests that the U.S. Supreme Court was incorrect in using the confidence of the witness as one of the criteria by which the reliability of testimony should be evaluated (Neil v. Biggers, 1972, p. 199).

\section{REFERENCES}

Anderson, D. C., Borkowskı, J. G. (1978). Experimental psychology. Glenview, IL: Scott, Foresman.

BARTSCH, R. (1987). Norms of language: Theoretical and practical aspects. London: Longman

Chambers, J. K., Trudgill, P. (1980). Dialectology. Cambridge: Cambridge University Press

Clifford, B. R. (1980). Voice identification by human listeners: On earwitness reliability. Law \& Human Behavior, 4, 373-394

DEFFENBACHER, K. A. (1985, May). Forensic and scientific issues in voice recognition: A commentary. Paper presented at the Midwestern 
Psychological Association Symposium, Forensic and scientific issues in voice recognition, Chicago.

DISNER, S. F. (1980). Evaluation of vowel normalization procedures. Journal of the Acoustical Society of America, 67, 253-261.

Francis, W. N. (1983). Dialectology: An introduction. New York: Longman.

Goldstein, A. G., Knight, P., Bailis, K., \& Conover, J. (1981). Recognition memory for accented and unaccented voices. Bulletin of the Psychonomic Society, 17, 217-220.

JoHnson, K. (1990). The role of perceived speaker identity in $F 0$ normalization of vowels. Journal of the Acoustical Society of America, 88, 642-654.

Labov, W. (1972), Sociolinguistic patterns. Philadelphia: University of Pennsylvania Press.

LAMBERT, W. E. (1967). A social psychology of bilingualism. In J. Macnamara (Ed.), Problems of bilingualism. Special issue of Journal of Social Issues, 23, 91-109.

LAVER, J. (1980). The phonetic description of voice quality. Cambridge: Cambridge University Press.

LAVER, J. (1989). Cognitive science and speech: A framework for research. In H. Schnelle \& N. O. Bernsen (Eds.), Logic and linguistics. Research directions in cognitive science: European perspectives (Vol. 2., pp. 37-70). Hove, England: Erlbaum.

LEMmon, C. R., \& GoGGIN, J. P. (1989). The measurement of bilingualism and its relationship to cognitive ability. Applied Psycholinguistics, 10, 133-155.

Macnamara, J. T. (1969). How can one measure the extent of a person's bilingual proficiency? In L. G. Kelly (Ed,), Description and measurement of bilingualism: An international seminar (pp. 80-97). Toronto: University of Toronto Press.

MCGEHEE, F. (1937). The reliability of the identification of the human voice. Journal of General Psychology, 17, 249-271.

MiLROY, L. (1986). Social network and linguistic focusing. In H. B. Allen \& M. D. Linn (Eds.), Dialect and language variation (pp. 367380). New York: Academic Press.
Mullennix, J. W., Pisoni, D. B., \& Martin, C. S. (1989). Some effects of talker variability on spoken word recognition. Journal of the Acoustical Society of America, 85, 365-378.

NEAREY, T. M. (1989). Static, dynamic, and relational properties in vowel perception. Journal of the Acoustical Society of America, 85 , 2088-2113.

Nell V. BIGgers, 409 U.S. 188 (1972).

Pollack, I., Pickett, J., \& Sumby, W. (1954). On the identification of speakers by voice. Joumal of the Acoustical Society of America. 26, 403-406

SASLOVE, H., \& YARMEY, A.D. (1980). Long term auditory memory: Speaker identification. Journal of Applied Psychology, 65, 111-116.

ThOMPSON, C. P. (1985a). Voice identification: Attempted recovery from a biased procedure. Human Learning. 4, 213-224.

Thompson, C. P. (1985b). Voice identification: Speaker identifiability and a correction of the record regarding sex effects. Human Leaming, 4, 19-27.

Thompson, C. P. (1987). A language effect in voice identification. Applied Cognitive Psychology, 1, 121-131.

TrUDGiLl, P. (1983). Sociolinguistics: An introduction to language and sociery. New York: Penguin.

UNDERwOOD, G. N. (1988). Accent and identity. In A. R. Thomas (Ed.), Methods in dialectology (pp. 406-427). Philadelphia: Multilingual Matters.

WOODWORTH, R. S. (1938). Experimental psychology. New York: Holt.

\section{NOTE}

1. Thanks are due an anonymous reviewer for making this suggestion.

(Manuscript received August 31, 1989; revision accepted for publication February 14, 1991.)

\title{
Notices and Announcements
}

\author{
Members of Underrepresented Groups: \\ Reviewers for Journal Manuscripts Wanted
}

On behalf of Memory \& Cognition and Psychonomic Society Publications, I invite you to contact me if you are interested in reviewing manuscripts for Memory \& Cognition. Please send a letter and a copy of your curriculum vita to me at the following address: Memory \& Cognition, Department of Psychology, Indiana University, Bloomington, Indiana 47405. The letter or the vita should contain your complete address (including an electronic mail address if one is available), telephone number, and area(s) of expertise. Our reviewers have published articles in peer-reviewed journals, a standard prerequisite for being selected as a reviewer.

Please note that reviewing manuscripts takes time and must be completed quickly. If you are asked to review a manuscript, you will be expected to provide a thorough and prompt review.

Margaret Jean Intons-Peterson Editor 